\section{Phenotypic antimicrobial resistance profile of isolates causing clinical mastitis in dairy animals}

\author{
Carlotta Ceniti, ${ }^{1}$ Domenico Britti, ${ }^{1}$ \\ Adriano Michele Luigi Santoro, ${ }^{2}$ \\ Rosanna Musarella, ${ }^{3}$ \\ Lucia Ciambrone, ${ }^{3}$ \\ Francesco Casalinuovo, ${ }^{3}$ \\ Nicola Costanzo ${ }^{1}$
}

${ }^{1}$ Department of Health Sciences, Magna Gracia University, Catanzaro;

${ }^{2}$ Department of Veterinary Medicine and Animal Production, University of Naples Federico II, Naples; ${ }^{3}$ Institute for Experimental Veterinary Medicine of Southern Italy, Catanzaro, Italy

\begin{abstract}
Mastitis is the most frequent and costly disease of lactating animals and is associated with a significant reduction in milk yield, increased cost and culling. Early and specific antibiotic based treatment reduces the severity of the disease. Over the years the extensive use of antimicrobials has led to increase antimicrobial resistance. The present study was designed to investigate the prevalence of microorganisms responsible for mastitis and their antimicrobial resistance pattern. A total of 282 milk samples were collected from different animal species (sheep, cows and goats) with clinical mastitis. Antimicrobial resistance was evaluated for Streptococcus spp. and Staphylococcus spp. In cow samples Streptococcus spp. represented the most frequently isolated genus (33.84\%), while Staphylococcus spp. was the most prevalent genus in sheep and goat samples (44.4 and $73.86 \%$, respectively). Gentamicin and chloramphenicol were found to be the most effective drugs against the tested isolates, while the highest resistance rates were observed for amoxicillin, ampicillin, tetracycline, trimethoprim-sulfamethoxazole.
\end{abstract}

\section{Introduction}

Mastitis is an inflammation of the mammary gland (Fox et al., 2001; Bradley, 2002) and is the most frequent and costly disease in dairy animals throughout the world (Gomes and Henriques, 2016). Mastitis causes decreased milk production and quality, decreased cheese yield, increased cost of treatment, labor and culling (Gomes and Henriques, 2016). The most frequent pathogen in small ruminant (Bergonier et al., 2003) and cows (Fox et al., 2001) is Staphylococcus aureus but mastitis is also caused by many other bacteria such us Streptococcus spp., Escherichia coli, Pseudomonas spp., and Mycoplasma spp. Currently, the use of antibiotics is the most common treatment (Gomes and Henriques, 2016) and $\beta$-lactams are the most frequently classes used for the treatment of mastitis. Additionally, mastitis therapy is commonly started before the results of antimicrobial susceptibility test of pathogens (Hendriksen et al., 2008) representing one of the most important reason for treatment failure. Moreover, this antibacterial strategy has many disadvantages including a low cure rate, increasing the presence of antibiotics residues and occurrence of antimicrobial resistance (Minst et al., 2012). Resistance to antibiotics may be acquired by spontaneously occurring genetic mutations and more commonly by the horizontal transfer of mobile DNA elements from a donor cell to another bacterial species (Chambers, 2001). Over the years, extensive use of antimicrobials has led to increasing resistant bacteria at alarming rate and has become a serious concern worldwide. In order to ensure suitable antibiotic therapy, the bacterial isolation and the evaluation of antibiotic susceptibility are essential. In addition, milk produced from animals with subclinical mastitis posed serious veterinary and epidemiology risk since its rich nutrient composition and neutral $\mathrm{pH}$ make it a good vehicle for the survival and growth of bacteria. Resistant bacteria may contaminate food products and they could be transmitted to humans through the food chain underlining the importance of pathogens surveillance. Hence monitoring pathogens and their antimicrobial resistance patterns are the need of the day. The aim of this study was to investigate the prevalence of microorganisms responsible for mastitis and their antimicrobial resistance in Catanzaro district (Italy).

\section{Materials and Methods}

\section{Sampling}

In 2016, a total of 282 milk samples were collected from animals (140, 110 and 32 from sheep, cows and goats respectively) with clinical mastitis bred in 125 dairy farms (60, 52 and 13 sheep, cows and goats dairy farms respectively) located in Southern Italy (Catanzaro, Calabria region). All the samples were obtained from routine
Correspondence: Nicola Costanzo, Department of Health Sciences, Magna Græcia University, viale Europa - Loc. Germaneto Edificio delle Bioscienze, 88100 Catanzaro (CZ), Italy.

Tel. +39.0961.3694203.

E-mail: costanzo.nic@unicz.it

Key words: Antibiotic resistance; Mastitis; Staphylococcus aureus.

Conflict of interest: the authors declare no potential conflict of interest.

Received for publication: 2 February 2017. Revision received: 18 April 2017.

Accepted for publication: 18 April 2017.

This work is licensed under a Creative Commons Attribution-NonCommercial 4.0 International License (CC BY-NC 4.0).

(C) Copyright C. Ceniti et al., 2017

Licensee PAGEPress, Italy

Italian Journal of Food Safety 2017; 6:6612

doi:10.4081/ijfs.2017.6612

submission of milk to the Institute for Experimental Veterinary Medicine of Southern Italy, Catanzaro. Samples were transported cooled to the laboratory and kept at $4^{\circ} \mathrm{C}$ before examination (within 24 h). From each sample, an amount of $10 \mathrm{ml}$ was ten-fold diluted in $90 \mathrm{ml}$ of a quarterstrength Ringer Solution (Oxoid Ltd., Hampshire, UK).

\section{Isolation and identification}

From each sample an amount of one $\mathrm{mL}$ was inoculated onto selective Baird-Parker, Columbia Blood and McConkey (Oxoid Ltd.) agar media for isolation of staphylococci, streptococci and coliform bacteria, respectively. Plates were incubated at $37^{\circ} \mathrm{C}$ per 24-48 hours. Colonies were presumptive identified based on morphology, hemolytic patterns and Gram strain. Confirmation was carried out using IDGNB (BioMérieux, Marcy l'Etoile, France) cards for gram-negative bacteria and IDGNP (BioMeriéux) cards for gram positive for Vitek 2 system (BioMérieux) following producer instructions.

\section{Antimicrobial susceptibility testing}

The most prevalent isolates were tested for their drug susceptibility using disc diffusion method against the following antibiotics: amoxicillin-clavulanate 20/10 $\mu \mathrm{g}$; ampicillin $10 \mu \mathrm{g}$; cefalotin $30 \mu \mathrm{g}$; cefotaxime $30 \mu \mathrm{g}$; ceftiofur $30 \mu \mathrm{g}$; clindamycin $2 \mu \mathrm{g}$; chloramphenicol $30 \mu \mathrm{g}$; gentamicin $10 \mu \mathrm{g}$; enrofloxacin $5 \mu \mathrm{g}$; erythromycin 15 $\mu \mathrm{g}$; kanamycin $30 \mu \mathrm{g}$; oxacillin $1 \mu \mathrm{g}$; peni- 
cillin 10 U.I.; sulfisoxazole $250 \mu \mathrm{g}$; tetracycline $30 \mu \mathrm{g}$; trimethoprim-sulfamethoxazole $1.25 / 23$ and tylosin $10 \mu \mathrm{g}$. Isolates were classified as resistant or susceptible towards the tested antimicrobials in accordance with breakpoints proposed by the Clinical and Laboratory Standards Institute (2007). Intermediate isolates were grouped with the resistant ones. Multidrug resistance was defined as resistance of 3 or more classes of antimicrobial agents (Schwarz et al., 2010).

\section{Results}

Out of 282 samples, 68 did not yield bacterial growth on culture, 52 were considered contaminated ( $>2$ bacterial species yielded) and in 162 a single bacteria strain was isolated. Table 1 shows the number and frequency of microorganism isolated from milk samples according to animal species.

Microorganisms isolated from sheep samples were identify as Staphylococcus aureus (20.14\%), Staphylococcus chromogenes (11.14\%), Staphylococcus epidermidis (11.14\%), Staphylococcus warneri (8.14\%), Enterobacter cloacae (6.14\%), Kocuria rosea (6.14\%), Staphylococcus simulans (6.14\%), Streptococcus uberis (5.14\%), Staphylococcus hominis subsp. hominis (5.14), Staphylococcus auricolaris

\section{(4.14\%).}

The most prevalent isolates in cow samples were Staphylococcus aureus (24.62\%), Streptococcus agalactiae (15.38\%), Streptococcus dysgalactiae (12.31\%), Enterococcus avium (10.77\%), Lactococcus spp. (10.77\%), Aerococcus viridians (9.23\%), Staphylococcus chromogenes (4.62\%) Streptococcus equisimilis (3.08\%). From the goat samples the predominant bacteria isolated was Staphylococcus aureus (44.44\%).

Staphylococcus spp. for sheep (69.31\%) and goat (77\%) samples and Streptococcus spp. for cow samples $(33.84 \%)$ resulted the most prevalent bacterial genera.

A total of 121 samples resulted positive for Staphylococcus spp. and Streptococcus spp. and were tested for antibiotic resistance; the percentage of isolates resistant to tested antibiotics is reported in Table 2.

Gentamicin, oxacillin, cefotaxime were the most effective drugs (all the isolates were sensible) against Staphylococcus spp., whereas all of Streptococcus spp. showed to be sensitive to ceftiofur and chloramphenicol.

Staphylococcus spp. showed to be resistant to ampicillin (34\% of isolates) followed by sulfisoxazole $(25 \%)$ trimethoprim-sulfamethoxazole (18\%), amoxicillinclavulanate $\quad(15.62 \%)$, clindamycin $(15.62 \%)$ tetracycline $(9 \%)$. Some resist- ances were also observed against enrofloxacin, chloramphenicol, erythromy$\operatorname{cin}(6 \%)$.

Most of Streptococcus spp. resulted resistant to tetracycline (57\%); the $42 \%$ of Streptococcus spp. isolates resulted resistant to clindamycin and the $28 \%$ resulted resistant to ampicillin.

Only 4 isolates were susceptible to all the antibiotics tested. The $25 \%$ of bovine isolates and the $17 \%$ of ovine isolates were multiresistant. Multi drug resistance occurred most frequently among amoxicillin, tetracycline and trimethoprim-sulfamethoxazole, and in the $\beta$-lactam antibiotics class, a majority of isolates resistant to ampicillin were also resistant to amoxicillin-clavulanate.

\section{Discussion}

According to the previous paper (Contreras et al., 2007), in our study the most representative bacteria genus isolated from sheep and goat mastitic milk was Staphylococcus spp. Unsurprisingly the most prevalent species was Staphylococcus aureus $(20.14 \%$ in sheep and $44.44 \%$ in goat) whose presence in sheep and goat milk has been widely demonstrated in Italy: Cortimiglia et al. (2015) evidenced in bulk tank sheep's milk a Staphylococcus aureus

Table 1. Number and percentage of isolates from mastitic milk according to animal species.

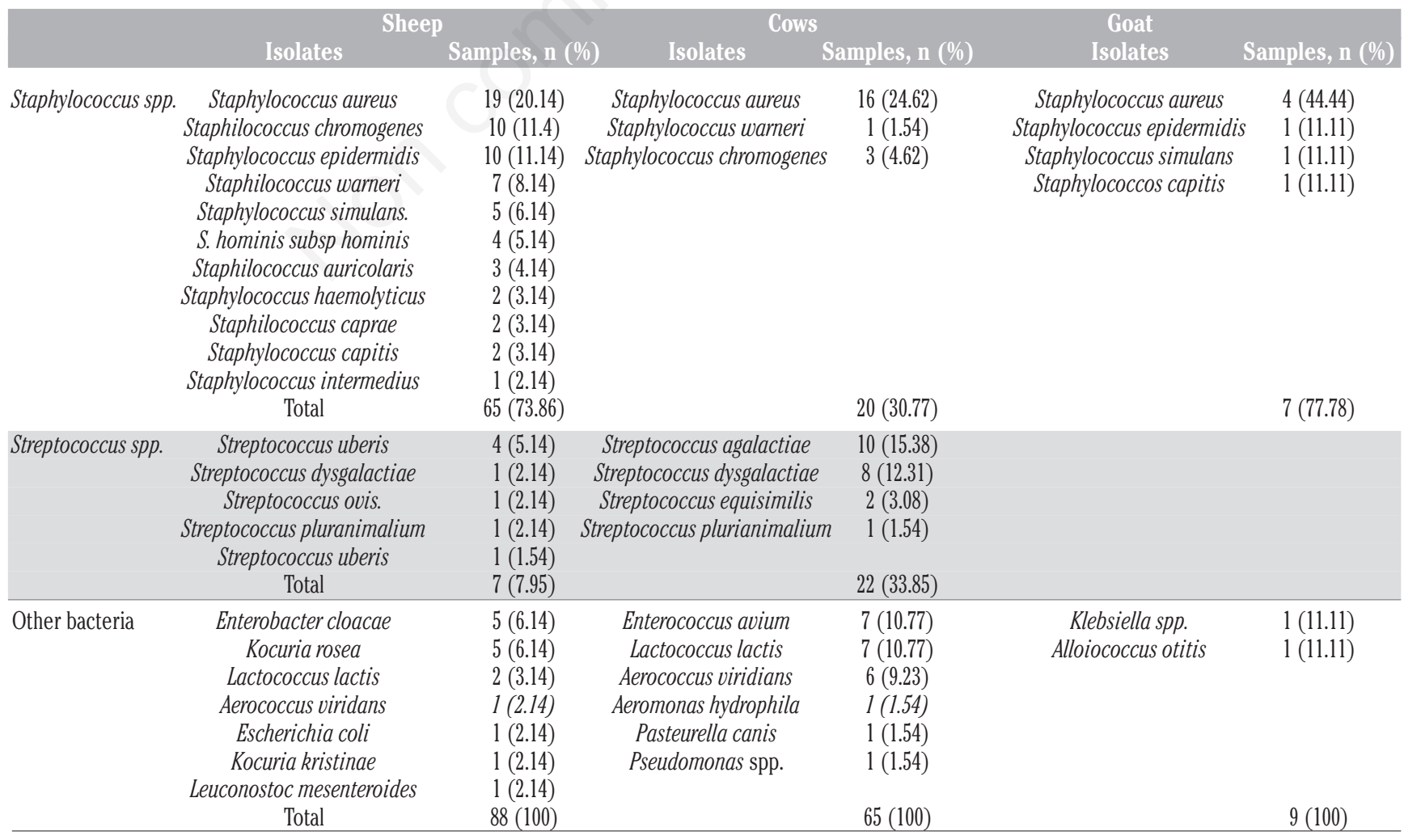


prevalence of $43 \%$, Spanu et al. (2013) in bulk tank goat's milk showed a prevalence of $76 \%$. On the other hand, the predominant bacterial genera isolated from cow samples was Streptococcus spp. (33.84\%) out of these samples, 10 were identified as Streptococcus agalactiae and 8 as Streptococcus dysgalactiae; the first is most often associated with cows and well adapted to the mammary gland whereas Streptococcus dysgalactiae is an environmental pathogen (Minst et al., 2012).

Our findings are in agreement with several other reports (Munsi et al., 2016; Chaffer et al., 1999; Minst et al., 2012; Iqbal et al., 2004) and are in contrast with other authors (Sumathi et al., 2008; Singh et al., 2016) who showed a higher prevalence of Staphylococcus spp. in cow mastitic milk. However in our work Staphylococcus spp. showed a high prevalence $(30.77 \%)$ too; indeed, as shown in Table 1, the main representative isolate was Staphylococcus aureus. It is well known that Staphylococcus aureus is frequently isolated in bovine clinical or subclinical mastitis (Moroni et al., 2006).

This high Staphylococcus aureus prevalence in sheep, cow and goat milk might pose a health risk to humans. It is well known that Staphylococcus aureus produces a spectrum of extracellular protein toxins and virulence factors which are thought to contribute to the pathogenicity of the microorganism. The staphylococcal enterotoxins are recognized agents of the staphylococcal food poisoning syndrome and may be involved in other types of infections with sequelae of shock in humans and animals (Akineden et al., 2001). In addition, many traditional caprine and ovine milk products are not subjected to pasteurization representing a potential source of staphylococcal food poisoning (Merz et al., 2016).

Lactococcus lactis has also been evidenced in 7 cow samples: normally used as a starter strain in several foods such as cheese, it has been linked, in recent years, to bovine mastitis cases (Wyder et al., 2011; Romero et al., 2011).

Enterococcus avium, as previously reported by Nam et al. (2009), has been evidenced in cow mastitic milk samples.

Our findings revealed a wide diffusion of antibiotic resistance to most of antimicrobials tested; even more concerning was the high prevalence of resistance and multiresistant isolates for those antimicrobials normally used for mastitis treatment such as $\beta$-lactams. It is well known that $\beta$-lactams (penicillins and cephalosporins) are widely used for intramammary treatment of bovine mastitis. Similar results were reported for cow milk by Rajala-Schultz et al. (2004) and Bhatt et al. (2011) and in other studies

Table 2. Antimicrobial resistance pattern of Streptococcus spp. and Staphylococcus spp. isolated from mastic milk samples.

\begin{tabular}{lcc} 
Antibiotics & \multicolumn{2}{c}{ Resistance (\%) } \\
& Streptococcus sp. & \\
Staplococcus spp.
\end{tabular}

carried out in Italy (Moroni et al., 2006). Only oxacillin showed high activity against staphylococci.

Cephalosporins showed greater antistaphylococcal and antistreptococcal activities than other $\beta$-lactams such as amoxicillin, accordingly to Moroni et al. (2006) who evidenced a good activity against Staphylococcus aureus for cephalosporins of first generation and third generation (cephalonium, cefoperazone). RajalaSchultz et al. (2004) reported that $63 \%$ of streptococci were resistant to cephalothin; in our study only $14 \%$ of Streptococcus spp. resulted resistant to cephalothin. Furthermore, cefotaxime and ceftiofur resulted highly efficient against staphylococci and streptococci respectively.

Lincosamides are commonly used for therapy of staphylococcal infection and are frequently used for the treatment of bovine mastitis (Wang et al., 2008). In the present study, clindamycin, showed low activity against Staphylococcus spp. and resulted more efficient against Streptococcus spp.

Additionally, Staphylococcus spp. resulted highly sensitive to gentamicin followed by enrofloxacin and erythromycin. This study also revealed chloramphenicol to be the most effective drug against streptococci. Similar antibiogram patterns were also reported by Bhatt et al. (2011), Iqbal et al. (2004) and Sumathi et al. (2008). This latter proved gentamicin to be the drug of choice against clinical mastitis in dairy cattle.

An interesting observation is that isolates had high resistance and multi resistance for tetracycline and trimethoprim-sulfamethoxazole as reported in other studies (Rajala-Schultz et al., 2004), although these molecules are only occasionally used for treating mastitis. Prescott (2000) suggests that sulfa-resistance is often carried along with tetracycline resistance in plasmids.

Although our results are in accordance with previous research, we have to considerer that comparison between different studies is difficult due to different susceptibility testing methods and different interpretative criteria being used to categorize isolates as susceptible or resistant. Antimicrobial test is useful to detect the most efficient drugs to contrast bacterial grow even though several factors can influence the overall susceptibility pattern of mastitis pathogens (Oliver et al., 2011).

\section{Conclusions}

The study showed that Streptococcus spp. and Staphylococcus spp. are the most frequent bacteria found in mastitic milk of 
cows and sheep/goats respectively. Of all samples, the main representative isolate turned out to be Staphylococcus aureus. Ceftiofur and chloramphenicol resulted the most effective antibiotics against streptococci, whereas isolates showed high resistance for tetracycline and clindamycin. Staphylococci resulted highly sensitive to gentamicin, cefotaxime, oxacillin and resistant to ampicillin and sulfisoxazole. The $25 \%$ of bovine isolates and the $17 \%$ of ovine isolates were multiresistant.

\section{References}

Akineden Ö, Annemüller C, Hassan AA, Lämmler C, Wolter W, Zschöck M, 2001. Toxin genes and other characteristics of Staphylococcus aureus isolates from milk of cows with mastitis. Clin Diagn Lab Immunol 8:959-64.

Bergonier D, De Crémoux R, Rupp R, Lagriffoul G, Berthelot X, 2003. Mastitis of dairy small ruminants. Vet Res 34:689-716.

Bhatt VD, Patel MS, Joshi CG, Kunjadia A, 2011. Identification and antibiogram of microbes associated with bovine mastitis. Anim Biotechnol 22:163-9.

Bradley AJ, 2002. Bovine mastitis: an evolving disease. Vet J 164:116-28.

Chaffer M, Leitner G, Winkler M, Glickman A, Krifucks O, Ezra E, Saran A, 1999. Coagulase-negative Staphylococci and Mammary Gland Infections in Cows. J Vet Med 46:70712.

Chambers HF, 2001. Antimicrobial agents general considerations. In: J.G. Hardman, L.E. Limbird, A.G. Gilman (eds.) Goodman \& Gilman's. The pharmacological basis of therapeutics. McGraw-Hill Medical, New York, NY, pp. 1143-70.

Clinical and Laboratory Standards Institute, 2007. Performance standards for antimicrobial disk and dilution susceptibility tests for bacteria isolated from animals. Approved standard. Clinical and Laboratory Standards Institute, Wayne, PA, USA.

Contreras A, Sierra D, Sánchez A, Corrales JC, Marco JC, Paape MJ, Gonzalo C, 2007. Mastitis in small ruminants. Small Ruminant Res 68:145-53.
Cortimiglia C, Bianchini V, Franco C, Caprioli A, Battisti A, Colombo L, Stradiotto K, Vezzoli F, Luini M, 2015. Prevalence of Staphylococcus aureus and methicillin-resistant S. aureus in bulk tank milk from dairy goat farms in Northern Italy. J Dairy Sci 98:2307-11.

Fox LK, Bayles KW, Bohach GA, 2001. Staphylococcus aureus mastitis. In: A. Honeyman, H. Friedman, M. Bendinelli (eds.) Staphylococcus aureus: infection and disease. Springer Science \& Business Media, US, pp 271-94.

Gomes F, Henriques M, 2016. Control of bovine mastitis: old and recent therapeutic approaches. Curr Microbiol 72:377-82.

Hendriksen RS, Mevius DJ, Schroeter A, Teale C, Meunier D, Butaye P, Greko C, 2008. Prevalence of antimicrobial resistance among bacterial pathogens isolated from cattle in different European countries: 2002-2004. Acta Vet Scand 50:1.

Iqbal M, Khan MA, Daraz B, Siddique U, 2004. Bacteriology of mastitic milk and in vitro antibiogram of the isolates. Pak Vet J 24:161-4.

Merz A, Stephan R, Johler S, 2016. Staphylococcus aureus isolates from goat and sheep milk seem to be closely related and differ from isolates detected from bovine milk. Front Microbiol 7:17.

Minst K, Märtlbauer E, Miller T, Meyer C, 2012. Short communication: Streptococcus species isolated from mastitis milk samples in Germany and their resistance to antimicrobial agents. J Dairy Sci 95:6957-62.

Moroni P, Pisoni G, Antonini M, Villa R, Boettcher P, Carli S, 2006. Short communication: Antimicrobial drug susceptibility of Staphylococcus aureus from subclinical bovine mastitis in Italy. J Dairy Sci 89:2973-6.

Munsi MN, Sarker NR, Khatun R, Alam $\mathrm{MK}, 2016$. Identification and antibiogram study of bacterial species isolated from milk samples of different locations in Bangladesh. Asian J Med Biol Res 1:457-62.

Nam HM, Lim SK, Moon JS, Kang HM, Kim JM, Jang KC, Kim JM, Kang MI, Joo YS, Jung SC, 2009. Antimicrobial resistance of enterococci isolated from mastitic bovine milk samples in Korea.
Zoonoses Public Health 57:59-64.

Oliver SP, Murinda SE, Jayarao BM, 2011. Impact of antibiotic use in adult dairy cows on antimicrobial resistance of veterinary and human pathogens: a comprehensive review. Foodborne Pathog Dis 8:337-55.

Prescott JF, 2000. Antimicrobial drug resistance and its epidemiology. In: J.F. Prescott, J.D. Baggot, R.D. Walker (eds.) Antimicrobial therapy in veterinary medicine. University Press, Iowa State, Ames, USA, pp. 27-49.

Rajala-Schultz P J, Smith KL, Hogan JS, Love BC, 2004. Antimicrobial susceptibility of mastitis pathogens from first lactation and older cows. Vet Microbiol 102:33-42.

Romero B, Morosini M, Loza E, Rodriguez-Banos M, Navas E, Canton R, del CampoR, 2011. Reidentification of Streptococcus bovis isolates causing bacteremia according to the new taxonomy criteria: still an issue? J Clin Microbiol 49:3228-33.

Schwarz S, Silley P, Simjee S, Woodford N, van Duijkeren E, Johnson AP, Gaastr W, 2010. Editorial: assessing the antimicrobial susceptibility of bacteria obtained from animals. J Antimicrob Chemother 65:601-4.

Singh N, Singh P, Patel RK, 2016. Isolation and identification of bacterial organisms from mastitic milk. J Livestock Sci7:46-8.

Spanu V, Scarano C, Virdis S, Melito S, Spanu C, De Santis EPL, 2013. Population structure of Staphylococcus aureus isolated from bulk tank goat's milk. Foodborne Pathog Dis 10:310-5.

Sumathi BR, Veeregowda BM, Amitha, RG, 2008. Prevalence and antibiogram profile of bacterial isolates from clinical bovine mastitis. Vet World 1:237-8.

Wang Y, Wu CM, Lu LM, Ren GWN, Cao XY, Shen JZ, 2008. Macrolide-lincosamide-resistant phenotypes and genotypes of Staphylococcus aureus isolated from bovine clinical mastitis. Vet Microbiol 130:118-25.

Wyder AB, Boss R, Naskova J, Kaufmann T, Steiner A, Graber HU, 2011. Streptococcus spp. and related bacteria: their identification and their pathogenic potential for chronic mastitis - a molecular approach. Res Vet Sci 91:349-57. 